\title{
CASE REPORT: Trichoderma longibrachiatum INFECTIONS IN A PEDIATRIC PATIENT WITH PERITONEAL DIALYSIS
}

\author{
(Reporte de caso: Infección por Trichoderma longibrachiatum en un paciente \\ pediátrico en peritoneodiálisis)
}

\author{
*Aroca,T.S.; **Piontelli, L.E. \& * *Cruz, Ch.R. \\ * Unidad de Cuidados Intensivos Pediátricos, \\ Hospital Carlos van Buren,San Ignacio 725, Valparaíso, Chile. \\ ** Universidad de Valparaíso, Escuela de Medicina, \\ Cátedra de Micología, Casilla 92 V. Valparaíso, Chile. \\ Email<eduardo.piontelli@uv.cl >
} Palabras clave: Trichoderma longibrachiatum, infección pediátrica, peritoneodiálisis. Key words:Trichoderma longibrachiatum, pediatric infections, peritoneal dialysis.

\begin{abstract}
A case report of an intrahospitalary Trichoderma longibrachiatum peritonitis in a female 13-year -old pediatric patient who had been previously diagnosed a terminal chronic renal insufficiency while being under peritoneal dialysis is presented. Nowadays literature recognizes certain members of the genus Trichoderma to be opportunistic pathogens of increasing occurrence in immunocompromised patients. The above girl received a satisfactory Amphoterin $B$ treatment yet she died due to an hypertensive emergency appearing secondarily to her basic pathology.
\end{abstract}

Increase of fungal infections in immunocompromised patients continues being higher in frequencies as well as in variety at the early stage of our 21 century (Santos et al., 2004; Richter et al., 1999; Rex et al., 1998; Guarro et al., 2003; PengNg et al., 2003). The internist during his routine clinic work has not only faced the presence of unknown exogenous agents but has also to improvise many times in an empirical way their treatment with available antifungal drugs, failing to know generally the sensibilities of these new agents in their field of work (Steinbach \& Perfect, 2003). Several members of the genus Trichoderma, a filamentous ascomycete microfungus bearing a wide cosmopolitan distribution and which rarely causes localized or disseminated infections in man, have become more frequently involved in serious clinic cases (Muñoz et al., 1997; Guarro et al., 1999; Richter et al., 1999; Chouaki et al., 2002) include most

\section{RESUMEN}

Se reporta un caso clínico de peritonitis intrahospitalaria por Trichoderma longibrachiatum en una paciente pediátrica de 13 años de edad, con antecedentes de insuficiencia renal crónica terminal, en tratamiento con peritoneodiálisis. La literatura actual reconoce a ciertos integrantes del género Trichoderma como patógenos oportunistas de creciente frecuencia en pacientes con compromiso inmune. La paciente fue tratada satisfactoriamente con Anfotericina B, sin embargo, falleció a causa de una emergencia hipertensiva secundaria a su patología de base.

of cases in literature. Trichoderma longibrachiatum is the most commonly involved in these infections, especially responsible for continuous ambulatory or hospitalary peritoneal dialysis or invasive infections in immunocompromised patients.

\section{Case report}

A female 13-year-old patient with focal and segmented glomerulosclerosis, chronic renal insufficiency, secondary arterial hypertension antecedents, in peritoneal dialysis since may 2004 and two events of multiresistant Enterobacter cloacal and E.aerogenes intrahospitalary peritonitis, respectively. She was treated with Ciprofloxacin, Imipenem and Vancomicin in the pediatric intensive care ward at the Hospital Carlos van Buren, fifth Region, Chile. 


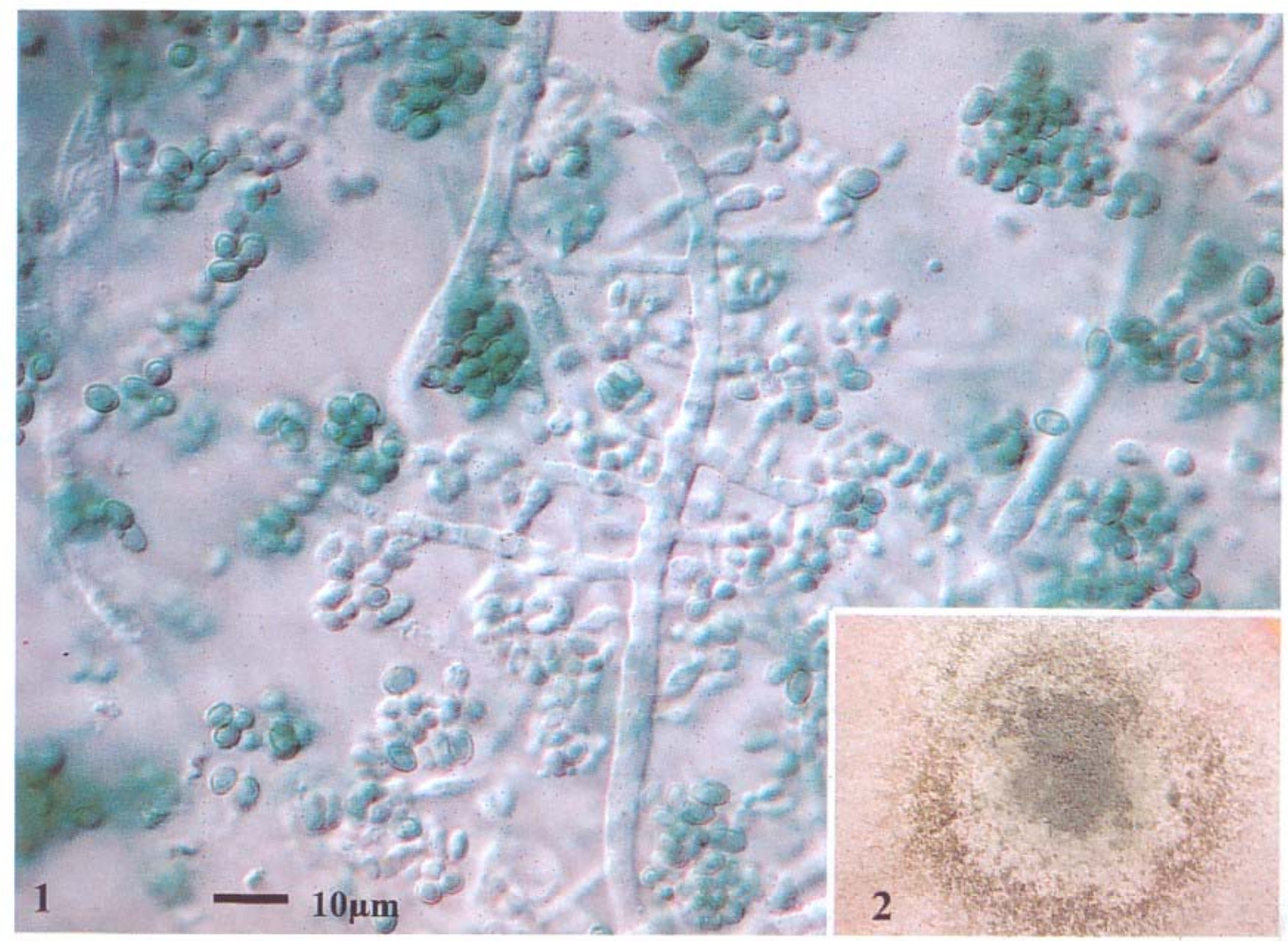

Figura 1-2. Trichoderma longibrachiatum. 1.- Conidiophore and conidia. 2.- Colony in PDA.

Since 23/7/04 she exhibits Acinetobacter baumanni sepsis and is received Ciprofloxacin and Imipenem. After a 10-day treatment, she shows a satisfactory evolution and recovers her conscience.

On 10/8/04 she shows turbid peritoneal fluid with purulent sediment, $76 \mathrm{mg} / \mathrm{lt}$ reactive $\mathrm{C}$ protein (PCR), 14300 blood leukocyte and peritoneal fluid cytochemical with 300 leukocytes and 2 blood red corpuscle. Later on she undergoes an intense abdominal pain and fever, and then Ciprofloxacin, Imipenem and Fluconazol are empirically suggested. Based on a nephrology evaluation, an hemodialysis is recommended together with her inclusion in the renal transplant program. With a $162 \mathrm{mg} /$ lt PCR, an abdominal scan is carried out resulting a chronic bilateral renal nephropaty and the absence of other pathological findings. The patient exhibits a regular evolution with an increased abdominal pain (PCR:191mg/lt) and a peritoneal fluid cytochemical of 1450 leucocytes, $83 \%$ polimorphonuclear and 50 erythrocytes.

According to the laboratory report (17/08), a growth of a green filamentous fungus, possibly similar to a strain of Aspergillus was detected in samples of peritoneal fluid whereby an initial Amphotericin B treatment in addition to indovenous Fluconazol is prescribed together with the suspension of the antibacterial treatment.Culture samples were sent to the Cátedra de Micología de la Escuela de Medicina de la Universidad de Valparaíso in order to undergo a mycological diagnosis which revealed the presence of Trichoderma longibrachiatum.

On 19/8/04 the patient shows an intrahospitalary pneumonia, Vancomicin and Imipenem are indicated while the antimycotic treatment with Amphotericin B $1 \mathrm{mg} / \mathrm{kg}$ plus daily indovenous Fluconazol 200mg is maintained. Successive samples of peritoneal fluid revealed a decrease in the number of T.longibrachiatum colonies with time. On 13/9/04 a double catheter is inserted in the yugular for hemodialysis, the peritoneal catheter is withdrawn, the antibiotic and antimycotic treatment is maintained with a good clinic response, an enteral feed probe is installed due to a severe malnutrition, gustatory disorders and dysphagia. However, the patient continued with high arterial tension readings despite the treatment with sodium nitroprusside, propanolol and nifedipine.

On $1 / 10 / 04$ the patient suffers an hypertensive emergency, convulsions and undergoes a cardiorespiratory arrest from which she could not recover in spite of 
the efforts of the personnel belonging to the ICU of the hospital.

\section{Mycology}

The first fungal isolates were cultured in Sabourad dextrose agar and Blood agar at $37^{\circ} \mathrm{C}$ and visually confirmed in the hospital laboratory to be similar to Aspergillus species and sent for their identification to the Cátedra de Micología de la Escuela de Medicina de la Universidad de Valparaíso where they were subcultured in PDA at $30^{\circ} \mathrm{C}$ and $\mathrm{CMA}$ at $40^{\circ} \mathrm{C}$ to measure colony radius in $65 \mathrm{~h}$. In PDA colonies grew rapidly, over $70 \mathrm{~mm}$ dia. and over $40 \mathrm{~mm}$ in CMA. In PDA conidia covered the entire colony surface tending to form concentric rings or forming crusts dark in colour (Fig.2) yellow to greenish yellow pigments diffusing through the agar (not forming at $40^{\circ} \mathrm{C}$ ) (Samuels et al.,1998).

Conidiophores in CMA are smooth, confluent pulvinate aggregates, with short secondary branches, with primary branches long and secondary ones usually short and rarely rebranched. Phialides typically cylindrical to lageniform, solitary, paired or 3 verticillate, intercalary phialides frequently produced $(5.8-11 \times 2-3,3 \mu \mathrm{m})$. Conidia in CMA, pale to medium green, oblong to ellipsoid, smooth walled, with a truncate base $(3,3.5,1 \times$ 2,4-3,2 $\mu \mathrm{m}$ ) (Fig.1). Chlamydospore frequent in old culture (CMA), terminal or intercalary, globose to subglobose $(4-12 \mu \mathrm{m})$.

This clinical strain was identified as T.longibrachiatum Rifai, and a living culture (CMEM 201) has been deposited in the mycology laboratory at the Escuela de Medicina de la Universidad de Valparaíso.

\section{DISCUSSION}

Localized and disseminated infections caused by members of the genus Trichoderma have been sporadically registered in literature since the firs: case described in a patient with chronic lung disease (Escudero et al.,1979). Most of existing cases have been reported in immunocompromised patients such as peritonitis under a recurrent peritoneal dialysis (Tanis et al. 1995), liver (Jacobs et al. 1992), bone marrow transplant (Richter et al.1999), brain abscess (Seguin et al.1995), skin infections, invasive sinusitis (Furukawa et al.1998), necroting stomatitis (Myoken et al.2002), renal transplant (Guarro et al. 1999), aplastic anemia (Muñoz et al. 1997) and invasive infections in different organs (Chouaki et al.,2000).

Allergenic features of mitospores and meiospore of many fungi can cause at the same time allergy symtoms, mainly fungal sinusitis, in which T.lungibrachiatum may become involved in those patients bearing atopy and asthma histories. Based on studies performed to characterize allergen release from spore before and after germination of different fungi such as Trichoderma viride, it is concluded that not all ungerminate spores release allergens yet all of them release them from their hyphae. Critical events that determine exposure to allergen might be an opportunity for spore to germinate after inhalation and increase of severity of lower respiratory tract disease (Tang et al., 2003).

Identification of Trichoderma species based on macro and micromorphological character remains problematic and difficult without experience in the genus, mainly the colony morphology which can be difficult to interpret as a taxonomic character (Gams \& Bisset, 1998). At present, the genus has been subdivided into 5 sections (Hypocreanum, Longibrachiatum, Pachybasium, Saturnisporum and Trichoderma) based primarily on micromorphological features, growth rates and growth at different temperatures (Bisset, 1984, 1991 a,b,c). However in spite of continuous progress in the genus since the contemporary findings of Rifai monography (1969) with his 9 "species aggregates", its taxonomy is still problematic at species level and morphological characters are not always useful in resolving evolutionary relationships between a telemorph and an anamorph (Hypocrea/Trichoderma)(Bisset, 1984 1991a,1991b, 1991c; Gams \&Bisset,1998; Kinderman et al., 1998). Modern keys and taxon descriptions are disperse in literature, (Rifai 1969; Bisset,1984,1991; Gams \& Bisset 1998 among others) yet considering its usefulness in our case report, we can mention those of Samuels et al.(1998), that by means of morphological and physiological characteristics make it possible to identify the Hypocrea schweinitzii complex and its anamorphs closely related to the species of the Section Longibrachiatum and Saturnisporum (the latter included in the Section Longibrachiatum by Gams \& Bisset, 1998). T.longibrachiatum and Hypocrea schweinitzii/T citrinoviride are the two most common species in the $T$. scheweinitzii complex and they are difficult to be separated by morphological distinctions and T.longibrachiatum might be considered to be a clonal derivate of T.orientalis (Samuels et al., 1998). At present, in addition to current morphological methods of identification, molecular schemes to differentiate the members of the Section Longibrachiatum can be used (Kuhls et al.,1997).

The isolation of Trichoderma species from diverse habitats is easy to be carried out through many cultural methods because of their rapid growth and capacity to produce a great number of conidia in a few days. The production of conidia (mitospores) from 
effused conidiophores or aggregates in fascicles or pustules is observed in many general culture media that are commonly used in the clinic laboratory (Sabouraud, PDA, MEA) yet they can also be obtained from other selective media (Gams \& Samuel, 1998 page 5).

Trichoderma longibrachiatum has very diverse habitats, soil in their variable substrata, wood, tree roots, herbs, senescent tissues, air and sometimes it is associated with the commercial growth of Agaricus bisporus (Seab,1996); Samuels et al.,1988, 2002).

Despite the ability of Trichoderma species to produce diverse metabolites and to exhibit an aggressive behaviour in nature, strains of this fungus are rarely associated with any type of disease in living plants. Mainly T.harzanium aggregates cause a significant loss of the commercial mushroom (Agaricus bisporus) (Samuels, 1966).

It can not be assured that the patient had not been at some moment, prior to the beginning of the infection, exposed to some short contacts with soil particles or vegetal material. The entry of this agent to the patients peritoneal fluid can be explained in different ways: the presence of its mitospores on the skin by aerial contamination, as a result of the personnel in charge of dialysis handling material contaminated with soil-dust microparticles and as an accidental contamination during the preparation of dialysis liquid. This latter situation has been reported in literature by introducing different fungal agents (Tanis et al., 1995; Febre et al.,1999). In this case the base clinic condition must be taken into account since it gave rise to an immunodepression, the use of long antimicrobials range, the intrahospitalary peritoneal dialysis and the secondary malnutrition, all of which contributed to a peritoneal infection caused by a fungal opportunistic. In spite of her deteriorated overall condition, the patient showed a satisfactory evolution after the indovenous antifungal treatment yet her sudden decease was due to an hypertensive emergency.

\section{REFERENCES}

Bissett, J. (1984). A revision of the genus Trichoderma. I. Section Longibrachiatum sect. nov. Can. J. Bot. 62:924-931

Bissett, J. (1991a). A revision of the genus Trichoderma. II. Infrageneric classification. Can. J. Bot. 69: 2357-2372

Bissett, J. (1991b). A revision of the genus Trichoderma. IV Additional notes on section Longibrachiatum sect. nov. Can. J. Bot. 69: 2418-24-20

Bissett, J. (1991c). A revision of the genus Trichoderma. III Section Pachybasium. Can. J. Bot. 69: 2373-2417

Chouaki, T.; Lavarde, V.; Lauchard, L.; Raccurd, C.P.; Hennenquin, C. (2002). Invasive infections due to Trichoderma species : Report of 2 cases finding of in vitro susceptibility testing and review of the literature. Clin. Infec. Dis. 35:1360-1367

Escudero, G.M.R.; Pino, E.C. \& Muñz, M.R. (1976) Micoma pulmonar causado por Trichoderma viride. Actas dermo-Sifiliográficas 67:673-680

Gams, W. \& Bisset. J. (1998). Morphology and identification of Trichoderma. In: C, P. Kubicek \& Harman, G.E. (Eds.). Trichoderma and Gliocladium. Basic biology, taxonomy and genetics. Vol 1. Bristol, Pennsylvania, Taylor \& Francis Inc. pp.3-34

Guarro, J.; Antolion-Ayala, M.I.; Gené, J.; Gutierrez.Calzada, J.; NievesDiéz, C.; Ortoneda, M. (1999). Fatal case of Trichoderma harzianum infection in a renal transplant recipient. J.Clin. Microbiol. 37:3751-3755

Guarro, J.; Aves, S.H.; Gené, J.; Grazziotin, N.A.; Mazzuco, R.; Dalmagro,C.; Capilla. J.; Zaror, L.; Mayayo, E. (2003). Two cases of subcutaneous infection due to Phaeoacremonium spp. J.Clin. Microbiol. 41:1332-1336

Furukawa,H.; Kusne, S.; Sutton, D.A.; Manez, R., Nichols, L.; AbuElmagd, K.; Skedros, D.; Todo, S.; Rinaldi, M.G. (1998). Acute invasive sinusitis due to Trichoderma longibrachiatum in a liver and small bowel transplant recipient. Clin. Infect. Dis. 26:487-489

Jacobs, F.; Byl, B.; Bourgeois, N.; Coremans-Pelseneer, J.; Florquin, S.; Depre, G.; Van de Stadt, J.; Adler, M. ;Gelin, M. ; Thys, J.P. (1992). Trichoderma viride infection in a liver transplant recipient. Mycoses 35:301-303

Kinderman, J.; El-Ayouti, Y.; Samuels, G.J.; Kubicek, C.P. (1988). Phylogeny of the genus Trichoderma based on sequence analysis of the internal transcribed spacer region 1 of the rDNA cluster. Fungal Genet. Biol. 24:298-309

Myoken, Y.; Sugata, T.; Fujita, Y.; Asaoku, H.; Fujihara, M.; Mikami, Y (2002). Fatal necrotizing stomatitis due to Trichoderma longibrachiatum patient with maliignant lynphoma: A case report. Int. J. Oral Maxillofac. Surg. 31:688-691

Nardoni, S.; Mancianti, F.; Sgorbini, M. \& Corazza,M. (2003). Evaluation of seasonal presence of fungal spores in three stables. Ippologia 14:6166

PengNg, K.; Soon, S.H.T.; LingNa, S. \& HuatTan, L. (2003). Sepedonium species: An emerging opportunistic fungal infection in a patient with a AIDS. Clin. Microbiol. Newsl. 25:20-22

Rex, J.M.; Walsh, T.J. \& Anaissie, E.J. (1988). Fungal infections in iatrogenic compromised host. Adv. Intern. Med. 43: 321-371

Rifai, M.S. (1969). A revision of the genus Trichoderma. Mycol. Papers. IMI, 116:1-56

Richter,S.; Cormican, M.G.; Pfaller, M.A.; Lee, C.K.; Gingrich, R.; Rinaldi, M.G.; Sutton, D.A. (1999). Fatal disseminated Trichoderma longibrachiatum infection in an adult bone marrow transplant patient: Species identification an review of the literature. J. Clin. Microbiol. 37:11541160

Samuels, G.J. (1996). Trichoderma: a review of biology and systematics 
Case report: Trichoderma longibrachiatum infections in a pediatric patient - Sandra Aroca et al.,

of the genus. Mycol. Res. 100: 923-935

Samuels, G.J. ; Petrini, O. ; Kuhls, K. ; Lieckfeldf, E. ; Kubicek, C.P. (1998). The Hypocrea schweinitzii complex and Trichoderma Sección Longibrachiatum. Study in Mycology, CBS, Baarn 41:1-54

Samuels, G.J.; Dodd, S.L.; Gams, W.; Cstlebury, L.A.; Petrini, O. (2002). Trichoderma species associated with the green mold epidemic of commercially grown Agaricus bisporus. Mycologia 94:146-170

Santos P.E., Piontelli, E.; Rosenzweig,S.; Zelazko M.; Galuzo L.; Baress C. (2004) Penicillium piceum: Patógeno emergente en un paciente pediátrico con enfermedad granulomatosa. Congreso Latinoamericano de Microbiología. Octubre, B. Aires (Abstract).

Seaby, D. (1996). Differentiation of Trichoderma taxa associsted with mushroom production. Plant Pathol. 45:905-912
Seguin, P.; Degeilh, B.; Grulois,I., Gacouin, A. ; Maugendre, S. Dufour, T. ; Dupont, B. ; Camus, C. (1995). Successfuil treatment of a brain abscess due to Trichoderma longibrachiatum after surgical resection. Eur.J.Clin. Microbiol. infect. Dis, 14:445-448

Tang, P.; Mohan; S.; Sigler, L.; Witterick, I., Summerbel, R..; Campbell, I.; Maste.M. (2003). Allergic fungal sinusitis associated with Trichoderma longibrachiatum. J. Clin. Microbiol. 41:5333-5336

Tanis,B.C.; van der Pijl, H.; van Ogtrop, M.L; Kibbelaar, R.E.; Chang,P.C (1995). Fatal fungal peritonitis by Trichoderma longibrachiatum complicating perotoneal dialysis. Nephrol. Dial. Transplant 10:116-116

Steinbach, W.J. \& Perfect, J.R. (2003). Newer antifungal therapy for emerging fungal pathogens. Int.J.Inf. Dis. 7:5-20 